Rev. Saúde públ., S. Paulo

$11: 455-64, \quad 1977$

\title{
PLANEJAMENTO DE UM LACTARIO PARA UM HOSPITAL ESCOLA DE 400 LEITOS
}

\author{
Sonia Aparecida Capasciutti * \\ Cristina Simões de Carvalho** \\ Helena Alves de Carvalho*** \\ Clélia Ciola ** \\ Ines de Fátima Peraçoli ****
}

RSPU-B $/ 378$

CAPAsciutti, S. A. et al. Planejamento de um lactário para um hospital escola de 400 leitos. Rev. Saúde públ., S. Paulo, 11:455-64, 1977.

RESUmo: Apresentação de modelo de planta física de um lactário, construido com o obietivo de sanar falhas constatadas durante observação efetuada em lactários de hospitais da cidade de São Paulo (Brasil), a partir de um conjunto de indicadores previamente selecionados e relacionados à construção da área fisica $e$ ao funcionamento organizado. São apresentados e discutidos fatores básicos a serem considerados no planejamento $e$ organização de um lactário.

Unitermos: Hospital, projeto e construção. Hospital, lactário.

\section{I NTROD U C A O}

O lactário é uma unidade obrigatória em todos os hospitais que mantêm leitos para crianças e berços para recém-nascidos. Destina-se ao preparo de leite e seus substitutos, a partir de técnicas adequadas, de modo a oferecer à criança uma alimentação sem risco mínimo de contaminação, ${ }^{3,6,8}$

Deve-se dar grande ênfase ao planejamento adequado da unidade. A eficiência das operações dentro de um lactário depende muito da seleção correta do local, espaço, arejamento e distribuição conveniente das áreas de trabalho, além da instalação de equipamentos apropriados, a fim de que todas as técnicas possam ser executadas de forma ordenada 1.

O lactário aqui apresentado foi planejado a partir de observações realizadas em estágios e visitas a alguns hospitais da cidade de São Paulo, no período de dezembro de 1974 a novembro de 1975, a saber: Hospital das Clínicas da Faculdade de

* Do Departamento de Nutrição da Kentinha S/A Inústria e Comércio. Estrada de Săo João Clímaco, 128. São Paulo, SP - Brasil.

* Da PLANOS - Planejamento e Organiza ção Hospitalar Ltda. Av. Brigadeiro Faria Lima, 1390. G82. São Paulo, SP - Brasil.

*** Do Instituto da Criança do Hospital das Clinicas da Faculdade de Medicina da UsP. Av, Dr. Enéas de Carvalho Aguiar. s/n. São Paulo, SP - Brasil.

**** Do Hospital Auxiliar de Cotoxó do Hospital das Clinicas da Faculdade de Medicina da USP. Rua Cotoxó, 1142. Săo Paulo, SP - Brasil. 
CAPAsciutri, S. A. et al. Planejamento de um lactário para um hospital escola de 400 leitos. Rer. Saúde públ., S. Paulo, 11:455-64, 1977.

Medicina da Universidade de São Paulo; Hospital dos Servidores Públicos do Estado de São Paulo; Hospital da Cruz Vermelha; Hospital Infantil Zona Norte; Hospital Albert Einsten; Hospital Municipal Infantil Menino lesus; Hospital do INPS (Brigadeiro); Hospital Anna Nery: Hospital 23 de Maio.

A partir desses estágios foram constatadas falhas no planejamento da área fisica de seus lactários. Foi verificado cue em alguns, as falhas se restringiram principalmente a:

- álea útil insuficiente;

-- existência de uma unica sala de preparo, tanto para sucos, chás e sopas como para leite;

-..- fluxo cruzado, prejudicando a eficiência do serviço;

-. equipamentos insuficientes e inadequados.

Apenas enl um dos luspitais visitados (Hospital Infantil Zuna Norte) toi constatada a existência de duas salas de preparo (uma para leite e outra para sucos, chás c sopas), verificando-se que, realmente. este tipo de distribuição da àrea física é - mais adequado à funcionalidade e contrule de contaminação em lactários.

A planta física aqui apresentada, do lactário de um Hospital Escola, idealizada para 400 leitos, objetiva sanar falhas encontradas nos lactários dos hospitais visitados.

Dos 400 leitos do Hospital Escola, 120 foram destinados à Maternidade e Berçário e 80 à Pediatria. Considerando-se o máximo de 6 mamadeiras por criança por dia, ter-se-ia, com todos os leitos ocupados, um movimento de 1.200 mamadeiras por dia. No entanto, o lactário apresentado poderá atingir uma capacidade máxima de 1500 mamadeiras diárias.

Este trabalho foi elaborado com o intuito de sugerir mudanças e transmitir a pessoas ligadas a Serviços de Nutrição, conhecimen- tos nodernos e técnicas atualizadas num planejamento para área hospitalar.

\section{Instalaçóes e equipamentos de um lactário}

Segundo dados encontracios na literatura, destacamos as características que devem ser observadas no planejamento de un lactário.

A localização do lactário ${ }^{\circ}$ depende do tipo de hospital, mas é necessário que sejam estudados os seguintes fatores:

- menor possibilidade de contaminação, particularmente proveniente de crianças e recém-nascidos doentes;

- afastamento tanto quanto possivel do movimento de pessoal, pacientes e visitantes;

- conveniencia na distribuição de fórmulas;

- supervisão adeyuada.

A área total destinada ao lactário, naturalmente varia com o numero de formulas a serem preparadas diariamente. Depencle tambén da configuraçāo das salas e du tipo de eyuipamento escolhido i

O lactário deve ter sala de lavagem separada da sala de preparo, pois assim há um menor perigo de contaminação"

Sua construção deve variar em tamanho de acordo com a finalidade do hospital, devendo ser acuela que melhor ofereça facilidades para limpeza e manutenção das condiçōes higiênicas exigidas pelo Código de Normas Sanitárias ${ }^{3}$.

Recomenda-se que o piso e as paredes de lactários sejam de superficie dura e te fácil limpeza, como ladrilho, cerânica, azulejos. As paredes não devem apresentar bordos ou ressaltos perto das janelas, que permitam o acúmulo de sujeira. Por lei, o pé direito minimo deve ser $3,05 \mathrm{~m}$, com pelo menos 1,50 n1 revestido de azulejo; no entanto, é recomendado revestimento até 0 teto. A parede não deve apresentar solução de continuidade com o piso. $O$ forro deve ser uma laje caiada, o que facilita a manutenção, $4 \cdot-8$ 
CAPASCIUTTI, S. A. et al. Planejamento de um lactário para um hospital escola de 400 leitos. Rev. Saúde públ., S. Paulo, 11:455-64, 1977.

A ventilação e iluminação devem ser observadas com o máximo cuidado, dependendo também destes fatores, o bom andamento do serviço. Se a localização for longe de áreas contaminadas, a ventilação por meio de janelas teladas fornece corrente contínua de ar livre ${ }^{3,6}$, se bem que somente janelas teladas não impedem a penetração de poeira no ambiente. Recomenda-se, então, a utilização de condicionadores de ar com filtro de poeira.

Os armários devem ser construidos de modo a facilitar o acesso aos seus interiores para perfeita limpeza. Dá-se preferência a mesas-armário com prateleiras inferiores. Armários de parede devem ser evitados ou, pelo menos, não localizados nas áreas de preparo de mamadeiras 1.

Deve haver um vestiário com armários e lavabos, exclusivo para o pessoal do lactário. Sempre que for possivel, deve existir uma sala de higienização pessoal, anterior à sala de preparo; é nesta sala que deve ser feita a suplementação do uniforme (aventais, gorros, pro-pés). 3,6

É aconselhável uma sala de utilidades para a guarda de utensilios de uso exclusivo do lactário (vassouras, panos), 3,6

A sala do nutricionista deve estar situada em local que permita fiscalização contínua de todo o serviço, através de repartições de vidro ou visores 1 .

$O$ equipamento deve ser de material não corrosível, resistente à ação continua de água e detergentes. Deve ser tal, que todas as suas partes possam ser facilmente limpas. E importante o uso de aparelho para esterilização terminal (autoclave) para a obtenção de segurança bacteriológica. ${ }^{1}$

A geladeira de um lactário deve ter portas que possam se abrir de uma sala para outra, a fim de que as mamadeiras cheias possam ser retiradas sem penetração de pessoas estranhas na sala de preparo.

Balcões, cubas e mesas de trabalho devem estar em tamanho proporcional ao número de mamadeiras preparadas e confeccionadas, preferivelmente em aço inoxidảvel.
O fogão não deve possuir forno, para facilitar a higiene do mesmo. São imprescindiveis a batedeira elétrica e balanças, com sensibilidade de 5 em $5 \mathrm{~g}$ e 10 em $10 \mathrm{~g} .^{7}$

Todos os equipamentos devem ser os mais modernos e práticos possiveis, principalmente para lavagem de material, mamadeiras, bicos e outros :

Lactários que utilizarão o método "Milton" de esterilização devem prever tanques ou cubas para essa finalidade. Estes tanques não devem ser de metal ou louça, mas de polietileno, recomendado para o caso. Uma cuba de $0,75 \times 0,45 \times 0,35 \mathrm{~m}$ de fundo permite esterilizar 70-100 mamadeiras de uma só vez '.

O método "Milton" consiste na imersão de mamadeiras e bicos previamente lavados numa solução de 1:80 de "Milton", durante 60 min., diluição e tempo que permitem completa esterilização deste material. $\mathrm{O}$ "Milton" é uma soluçâo de hipoclorito de sódio a $1 \%$. Não oferece toxicidade, devendo as mamadeiras serem usadas ao se retirar da cuba, sem necessidade de laválas. ${ }^{3}$

\section{LOCALIZAÇÃO E DETALHES DE CONSTRUÇÃO SUGERIDAS}

\section{1 -Localização:}

O lactário deverá estar localizado próximo ao berçário, porém, naturalmente, sem haver contato entre lactário e sala de berços. Recomenda-se esta localização por haver menor circulação de pessoas e materiais que possam aumentar o risco de contaminação do local, o que seria mais difícil de controlar na área de Serviço de Nutrição e Dietética on na Pediatria.

\section{2 - Detalhes de Construção:}

2.2.1 - Pé-direito: đeverá ser de 3,50m;

2.2.2 - Revestimento: as paredes e pisos deverão ser revestidas por material duro e de fácil limpeza, recomendando-se azulejos para as 
CAPASCiUtTi, S. A. et al. Planejamento de um lactário para um hospital escola de 400 leitos. Rov. Saúde públ., S. Paulo, 11:455-64, 1977.

paredes e cerâmica para o piso. Listes deverão ser assentados sem solução de continuidade, tendo todos os cantos, superiores, inferiores e laterais arredondados, o que evitará o acúmulo de sujeira, que poderia ser um foco de contaminação. Não deverá haver ralos no interior das salas de preparo, ficando estes na entrada do lactário; sendo assim, o lactário deverá ser lavado de dentro para fora;

2.2.3 - Forro: a caiação será preferida a outro tipo de pintura, por não impermeabilizar o teto. Isso é importante porque sendo o lactário uma área na qual pode haver condensação de vapores, se o teto for impermeável, a água condensada carreará toda a sujeira acumulada;

2.2.4 - Janelas: deverão ser amplas para facilitar a iluminação natural. Serão fixas, do tipo visor, a fim de evitar contaminação através de meio exterior. Como não há possibilidade de se manter ventilação natural, esta será substituida por condicionadores de ar com filtro de poeira.

\section{DISTRIBUIÇÃO DA AREA E EQUIPAMENTOS DO LACTÁRIO}

A área total do lactário será de $220,18 \mathrm{~m}^{2}$, assim distribuidos: (vide planta anexa).

\section{1 - Sala de preparo do leite:}

3.1 .1 - área: $7,00 \times 5,40 \mathrm{~m}=38,15 \mathrm{~m}^{2}$

3.1.2 - finalidade: destinar-se ao preparo das diferentes fórmulas lácteas, requeridas para a alimentação infantil;

3.1.3 - equipamentos:

- duas autoclaves, para esterilização terminal, medindo cada uma
$800 \times 1000 \times 1800 \mathrm{~mm}$ de altura. Sua parte posterior estará na sala de lavagem, economizandose espaço na sala de preparo de leite; (21)

- coifa sobrepondo as autoclaves (21-A), medindo aproximadamente $2000 \times 400 \mathrm{~mm}$ de largura, para exaustão dos vapores provenientes das autoclaves. $\mathrm{Na}$ comunicação do duto da coifa com o exterior, deverá haver um filtro de poeira construido à base de fibra de vidro sintética;

- fogão sem forno, com quatro queimadores médios, medindo $1200 \times 800 \times 850 \mathrm{~mm}$ de altura; (13)

- batedeira elétrica com capacidade para 20 litros; (14)

- balança com capacidade de $2 \mathrm{Kg}$ e sensibilidade de $5 \mathrm{~g}$;

- refrigerador "pass-throug", medindo $2400 \times 900 \times 1800 \mathrm{~mm}$ de altura, dotado de quatro portas, em cada face sendo duas superiores e duas inferiores, destinado à guarda e distribuição das mamadeiras; (19)

- carro em aço inoxidável, medindo $950 \times 600 \mathrm{~mm}$ de largura, constituido de dois planos. Destinar-se-á a levar as mamadeiras, em galheteiros, até o refrigerador "pass-through". A fim de facilitar o manejo, estes carros serão construídos de tal forma que as alturas de seus planos coincidam com as dos apoios onde ficarão os galheteiros, tanto na autoclave como no "pass-through". Para evitar contaminação este carrinho não abandonará o local; (18)

- tampos de aço inoxidável, assentados em mureta de alvenaria, com $850 \mathrm{~mm}$ de altura, apresentando medidas e finalidades diferentes: 
CAPASCIUTTI, S. A. et al. Planejamento de um lactário para um hospital escola de 400 leitos. Rev. Saúde públ., S. Paulo, 11:455-64, 1977.

a) em " $L$ ", rebaixado medindo no seu total $4900 \times 750 \mathrm{~mm}$ de largura, dotado de duas cubas geminadas, medindo $500 \times 450 \mathrm{x}$ $300 \mathrm{~mm}$ de fundo. Este tampo destina-se ao enchimento das mamadeiras, apresentando prateleira inferior em aço inoxidável a $300 \mathrm{~mm}$ do piso; (12)

b) simples, liso, medindo $2700 \mathrm{x}$ $750 \mathrm{~mm}$ de largura, destinado ao resfriamento das mamadeiras após terem sido autoclavadas, com prateleira inferior; (20)

c) simples, liso, medindo $1400 \mathrm{x}$ $750 \mathrm{~mm}$ de largura, sobre o qual ficará a balança. Será dotado de uma prateleira na parte inferior para guarda de latas de leite, açúcar, etc. .; (15)

- mesa de aço inoxidável, em dois planos medindo $2400 \times 850 \times 850 \mathrm{~mm}$ de altura, destinada a receber os latões cheios com as diferentes concentrações de leite; (17)

3.2 - Sala de preparo de chás, sucos e sopas :

3.2 .1 - área: $7,00 \times 5,40=38,15 \mathrm{~m}^{2}$;

3.2.2 - finalidade: destinar-se-á ao preparo de chás, sucos e sopas requeridos para a alimentação infantil;

\subsection{3 - equipamentos:}

- fogão sem forno, com quatro queimadores médios, medindo $1200 \times 800 \times 850 \mathrm{~mm}$ de altura; (13)

- liquidificador, tipo doméstico; (25)

- extrator de suco, tipo doméstico; (26)

- refrigerador, tipo doméstico, medindo $850 \times 700 \times 1800 \mathrm{~mm}$ de altura; (22)
- balança con capacidade para 5 $\mathrm{Kg}$ e sensibilidade de $10 \mathrm{~g}$; (24)

- armário, tipo "pass-through", de aço inoxidável, medindo $2400 \mathrm{x}$ $900 \times 1800 \mathrm{~mm}$ de altura, dotado de quatro portas em cada sala, sendo duas inferiores e duas superiores, destinado à passagem de mamadeiras com chás, sucos e sopas para a sala de distribuição; (29)

- carro em aço inoxidável, idêntico ao da sala de preparo de leite, destinado ao transporte de mamadeiras no interior da sala; (18)

- tampos de aço inoxidável, assentados em mureta de alvenaria, com $850 \mathrm{~mm}$ de altura, e apresentando prateleira inferior, com medidas e finalidades diferentes:

a) em ' $L$ ", rebaixado, medindo $9000 \times 750 \mathrm{~mm}$ de largura. Um dos seus lados é destinado ao preparo de chás e o outro ao enchimento de mamadeiras; (27)

b) simples, rebaixado, medindo $3600 \times 750 \mathrm{~mm}$ de largura, com duas cubas geminadas medindo $500 \times 450 \times 300 \mathrm{~mm}$ de fundo. Sobre este tampo ficarão liquidificador, extrator de suco e balança; (23)

- mesa de aço inoxidável, medindo $2400 \times 750 \times 850 \mathrm{~mm}$ de altura, com a mesma finalidade da mesa da sala de preparo de leite; (17)

\section{3 - Sala de Distribuição:}

3.3.1 - área: $4,80 \times 6,00 / 3,60=23,04 \mathrm{~m}^{2}$

3.3.2 - finalidade: local para a retirada das mamadeiras prontas, através de "pass-throug", para distribuição às enfermarias;

3.3.3 - equipamentos:

- carro em aço inoxidável, idêntico ao utilizado na sala de preparo de leite, destinado ao transporte das 
CAPASCIUTTI, S. A. et al. Planejamento de um lactário para um hospital escola de 400 leitos. Rev. Saúde públ., S. Paulo, 11:455-64, 1977.

mamadeiras de "pass-through" até as enfermarias; (18)

- banho-maria em aço inoxidável, medindo $1600 \times 1500 \times 850 \times 400 \mathrm{~mm}$ de profundidade, para aquecimento das mamadeiras; (31)

\section{4 - Sala de Lavagem:}

3.4 .1 - área: $10,90 \times 4,30=52,32 \mathrm{~m}^{2}$

3.4.2 - finalidade: destinar-se-á à lavagem de todas as mamadeiras, bicos e arruelas;

3.4.3 - equipamentos:

- tampo em "J" de aço inoxidável, assentado em mureta de alvenaria, de $850 \mathrm{~mm}$ de altura. O tampo mede no seu total $18200 \times 750$ mm de largura (8). Nele pode-se distinguir três setores diferentes, de acordo com suas finalidades:

a) para lavagem de bicos e arruelas das mamadeiras, contando com uma cuba para remolho, duas para lavagem e uma para enxaguadura. Cada cuba mede $500 \times 450 \times 300 \quad$ m111 de fundo;

b) para lavagem dos vidros de mamadeiras, contando com duas cubas para remolho, duas para lavagem e uma para enxaguadura, cada cuba medindo $500 \times 450 \times 300 \mathrm{~mm}$ de fundo. Os carros entrarão com as mamadeiras sujas, indo até o meio do tampo maior, distribuindo bicos à esquerda e vidros de mamadeiras à direita;

c) para lavagem de latões, panelas, galheteiros, existem duas cubas geminadas e uma para enxaguadura, situadas no fúndo da sala e apresentando na lateral direita (onde não há cubas), uma prateleira inferior, gradeada, fixada a $300 \mathrm{~mm}$ do piso para apoio das panelas. Cada cuba mede $700 \times 500 \times 400 \mathrm{~mm}$ de fundo;
Este tampo será dotado de um guichê com porta guilhotina (11a), comunicando-se com a sala de preparo de chás, sucos e sopas, por onde serăo passados os utensilios (omo panelas e latões. Para a passagem de mamadeiras e bicos limpos existirá uma cuba de polietileno, medindo $800 \times 550 \mathrm{x}$ $400 \mathrm{~mm}$ de profundidade, estando metade dela na sala de preparo e metade na sala de lavagem. Não há parede separando as duas salas dentro dessa cuba: a separaçăo é feita pela solução esporicida que constantemente ocupa toda a cuba, mantendo-a cheia (método "Milton" de esterilização). Nesta solução é que as mamadeiras limpas são mergulhadas e, como há um ligeiro declive, os funcionários na sala de preparo as recolhem. Não há necessidade desta comunicação entre a sala de preparo de leite e a de lavagem, pois as mamadeiras com leite serão autoclavadas; (9)

- tampo de aço inoxidável, simples, liso, medindo $1900 \times 750 \mathrm{~mm}$ de largura, com um guichê com porta guilhotina (11b) para a passagem de mamadeira e bicos limpos para a sala de preparo de leite. Será assentado sobre mureta de alvenaria de $850 \mathrm{~mm}$ de altura, e dotado de duas prateleiras, uma inferior e outra intermediária, para guardar os detergentes, etc. para uso imediato. (10)

- duas cubas sobre rodas, medindo cada uma $1500 \times 400 \times 300 \mathrm{~mm}$ de profundidade, contendo solução esporicida, destinadas ao transporte de bicos limpos até o guichề de passagem para a sala de preparo; (7) 
CAPASCIUTTI, S. A. et al. Planejamento de um lactário para um hospital escola de 400 leitos. Rev. Saúde públ., S. Paulo, 11:455-64, 1977.

Obs.: - Existem no mercado aparelhos para higienização de frascos de laboratório, que podem, mediante a substituição de um pequeno acessório, ser utilizados para lavagem de frascos de mamadeiras. No caso da disponibilidade de verba, o hospital deve optar por esse recurso, evitando-se a lavagem manual dos frascos.

\section{5 - Sala de utilidades:}

3.5 .1 - área: $3,70 \times 3,60=13,32 \mathrm{~m}^{2}$

3.5.2 - finalidade: guarda de material de limpeza e estoque de equipamentos do lactário que serão futuramente usados (panelas e outros);

\section{5 .3 - equipamentos:}

- mesa de escritório, medindo $1000 \mathrm{x}$ $600 \times 850 \mathrm{~mm}$ de altura, para funcionário que procederá ao registro de entrada e saída de material estocado; (5)

- cadeira; (6)

- armário em aço inoxidável, em "U", medindo $8300 \times 500 \times 1800 \mathrm{~mm}$ de altura no seu total, com prateleiras em dois lados e sem prateleiras em outro, para a guarda de materiais;

3.6 - Sala do nutricionista:

3.6 .1 - área: $2,40 \times 2,40 \mathrm{~m}=5,76 \mathrm{~m}^{2}$

3.6.2 - finalidade: destinar-se-á ao nutricionista, que desta sala terá condições de supervisionar todo 0 Serviço: entrada e saida de funcionários, preparo das mamadeiras, bem como sua distribuição;

\subsection{3 - equipamentos:}

- mesa de escritório, medindo $900 \mathrm{x}$ $600 \times 850 \mathrm{~mm}$ de altura; (33)

- cadeira;
- arquivo do lactário, em aço pintado, medindo $600 \times 500 \times 1500 \mathrm{~mm}$ de altura; (35)

- armário de aço pintado, medindo $600 \times 300 \times 1800 \mathrm{~mm}$ de altura, para uso pessoal do nutricionista; (32)

- estante de madeira, medindo $1400 \times 400 \times 1800 \mathrm{~mm}$ de altura; (34)

3.7 -Vestiários (um comunicando-se com a sala de preparo de leite e outro com a sala de preparo de chás)

3.7.1 - área: $4,80 \times 2,45 \mathrm{~m}=11,76 \mathrm{~m}^{2}$, cada um;

3.7.2 - finalidade: é indispensável a existência dessas salas para complementação de roupa, como aventais, toucas e pro-pés esterilizados;

3.7.3 - equipamentos:

- armário de aço pintado, medindo $2200 \times 500 \times 1800 \mathrm{~mm}$ de altura, para guarda de material; (30)

3.8 - Vestiários e sanitários (um vestiário feminino e um masculino cada um com um chuveiro e dois sanitários)

3.8.1 - área: $3,60 \times 3,60 \mathrm{~m}=12,96 \mathrm{~m}^{2}$, cada um;

3.8.2 - finalidade: servir apenas aos funcionários do lactário, como prevenção à contaminação;

3.8.3 - equipamentos:

- doze armários de aço pintado, medindo $500 \times 400 \times 400 \mathrm{~mm}$ de altura, cada um, sendo seis na parte superior e seis na parte inferior; (3)

Obs.: - todos os tampos de aço inoxidável deverão ser construidos em chapa $n^{\circ} 16$, padrão americano 304 , liga $18: 8$.

\section{9 - Sala das máquinas:}

Devido a disposição das salas de preparo a sugestão é instalar dois condicionadores 
LAfASCIUTTI, S. A. et al. Planejamento de um lactário para um hospital escola de 400 leıtos. Rev. Śaúde públ., S. Paulo, 11:455-64, 1977.

de ar com capacidade de 3 TR (toneladas de refrigeraçao) e $5 \mathrm{TR}$, ao lado do lactário, sen.to a distribuição de ar nas salas de preparo de leite e chás, sucos e sopas, feitas através de dutos construidos em chapas de aço galvanizado e bocas de ar do tipo grelhas de dupla deflexão (horizontal e vertical). Os dutos serão fixados a cerca de $300 \mathrm{~mm}$ do teto e deverão ser corbertos por um forro falso.

O retorno de ar deverá ser feito através de um trecho de duto construído também em chapa de aço galvanizado e de bocas de ar do tipo grelha de simples deflexâo. Os dutos que passam por ambientes não refrigerados deverão ser revestidos com uma camada de material isolante.

Nesta sala é prevista uma tomada de ar exterior para cada máquina, que tem por finalidade proporcionar a renovação de ar no ambiente condicionado.
Características de cada aparelho:

- capacidade: 3TR para sala de chás, sucos e sopas

5TR para sala de leite

- temperatura condicionada: em torno de 20 a $24^{\circ} \mathrm{C}$

- construção: chapas de aço galvanizado

- damper (ou registro) tipo borboleta incorporado à peça

- baixa perda de pressão

- material das grelhas: alumínio

- material do damper: chapa de aço preta pintada

- filtro de poeira: na tomada de ar exterior haverá uma camada filtrante colocada em gaveta, entre o damper e a grelha. Caracteristica desse filtro:

- purificação: - 93\% para particulas entre 0,5 e $5 \mu$

- construção: - fibras finas de vidro sintético.

RSPU-B/378

CAPASclurti, S. A. et al. [Planning of a milk dispensary for a 400 bed training hospital] Rev. Saúde públ., S. Palllo, 11:455-64, 1977.

ABSTRACT: A milk dispensary physical plant pattern that was built with the aim of keeping out errors found during visits to hospital milk dispensaries in the city of $S$. Paulo is presented. The pattern was built bearing in mind a set of pre-selected points regarding the building area and the perfect functioning of the system. Basic aspects in the project and organization of a milk dispensary are introduced and discussed.

Uniterms: Hospital, design and construction. Hospital, milk dispensary.

\section{REFERENCIAS BIBLIOGRAFICAS}

1. AMERICAN HOSPITAL ASSOCIATION. Lactario do hospital. São Paulo, Faculdade de Higiene e Saúde Pública da USP. 1958

2. ARNOLDI, L. N. Organização de Lactário. [Trabalho apresentado na $4 \mathrm{a}$. Reunião Nestlé de Nutrição Aplicada para Chefes de Lactário, São Paulo, 1969]

3. DIOGO, S. M. Lactário de um hospital: organização e funcionamento. Rev. paul. Hosp., 11(6):27-36, 1963.

4. HAFEZ, S. Lactário [Trabalho apresentado no Curso Nestlé de Enfermagem Neonatal, São Paulo, 1969]
5. HOFER, E. Investigações experimentais e práticas pelo método "Milton" na esterilização de mamadeiras. O Hospital, Rio de Janeiro, $\mathbf{7 1 : 9 5 7 - 7 0 , ~} 1967$.

6. KUMAGaI, Y. O lactário de um hospital de 300 leitos. Rev, paul. Hosp., 14(10): 34-44, 1966.

7. LASKANI, O. Planta fisica do lactario de um hospital. São Paulo, Faculdade de Saúde Pública da USP. Departamento de Nutrição, 1975. [Apostila]

8. VOGHT, D. Lactário, Rev. paul. Hosp., 19 (10) : 16-25, 1971

Recebido para publicacão em 08/09/1976. A provado para publicaça em 17/12/1976. 
LAPASCIUTTI, S. A. et al. Planejamento de um lactário para um hospital escola de 400 leitos. Rev. Saude públ., S. Faulo, 11:455-64, L9\%.

\section{$A N E X O$}

\section{LISTAGEM DE EQUIPAMENTOS DO LACTÁRIO}

1 - Chuveiro

2 - Lavatório

3 - Roupeiro (12 armários, sendo 6 na parte superior e 6 na parte inferior)

4 - Armário, sendo um lado com prateleiras

5 - Mesa de escritório

6 - Cadeira

7 - Cubas sobre rodas

8 - Tampo de aço inox com 4 pares de cubas geminadas e 4 simples

9 - Cuba de polietileno

10 - Tampo de aço inox, com guichê de passagem

11 - Guichê com porta guilhotina para passagem de material

12 - Tampo de aço inox, com duas cubas geminadas

13 - Fogão com quatro queimadores médios

14 - Batedeira elétrica, com capacidade para 20 litros

15 - Tampo de aço inox, com prateleira na parte inferior

16 - Balança de mesa com capacidade para $2 \mathrm{Kg}$

17 - Mesa de aço inox

18 - Carro com dois planos

19 - Refrigerador "pass-through"

20 - Tampo de aço inox

21 - Autoclaves

21-A: Coifa
22 - Refrigerador Loméstico

23 - Tampo de aço inox com duas cubas geminadas

24 - Balança de mesa com capacidade para $5 \mathrm{Kg}$

25 - Liquidificador

20 - Extrator de sucos

27 - Tampo de aço inox

28 - Filtro

29 - Armário "pass-through" de aço inox

30 - Roupeiro

31 - Banho-maria

32 - Armário

33 - Mesa de escritório

34 - Estante

35 - Arquivo do lactário

36 - Toalheiro

37 - Cesto de papéis

38 - Grelha de insuflamento de dupla deflexão - 20" x 8" com capacidade de 600 CFM

39 - Grelha de insuflamento de dupla deflexão - 24" x 12" com capacidade de 1000 CFM

40 - Grelha de insuflamento de simples deflexão - 20 " $\times 8$ "

41 - Condicionador de ar para sala de preparo leite

42 - Condicionador de ar para sala de preparo chás, sucos e sopas

43 - Tomada de ar exterior com filtro de poeira 


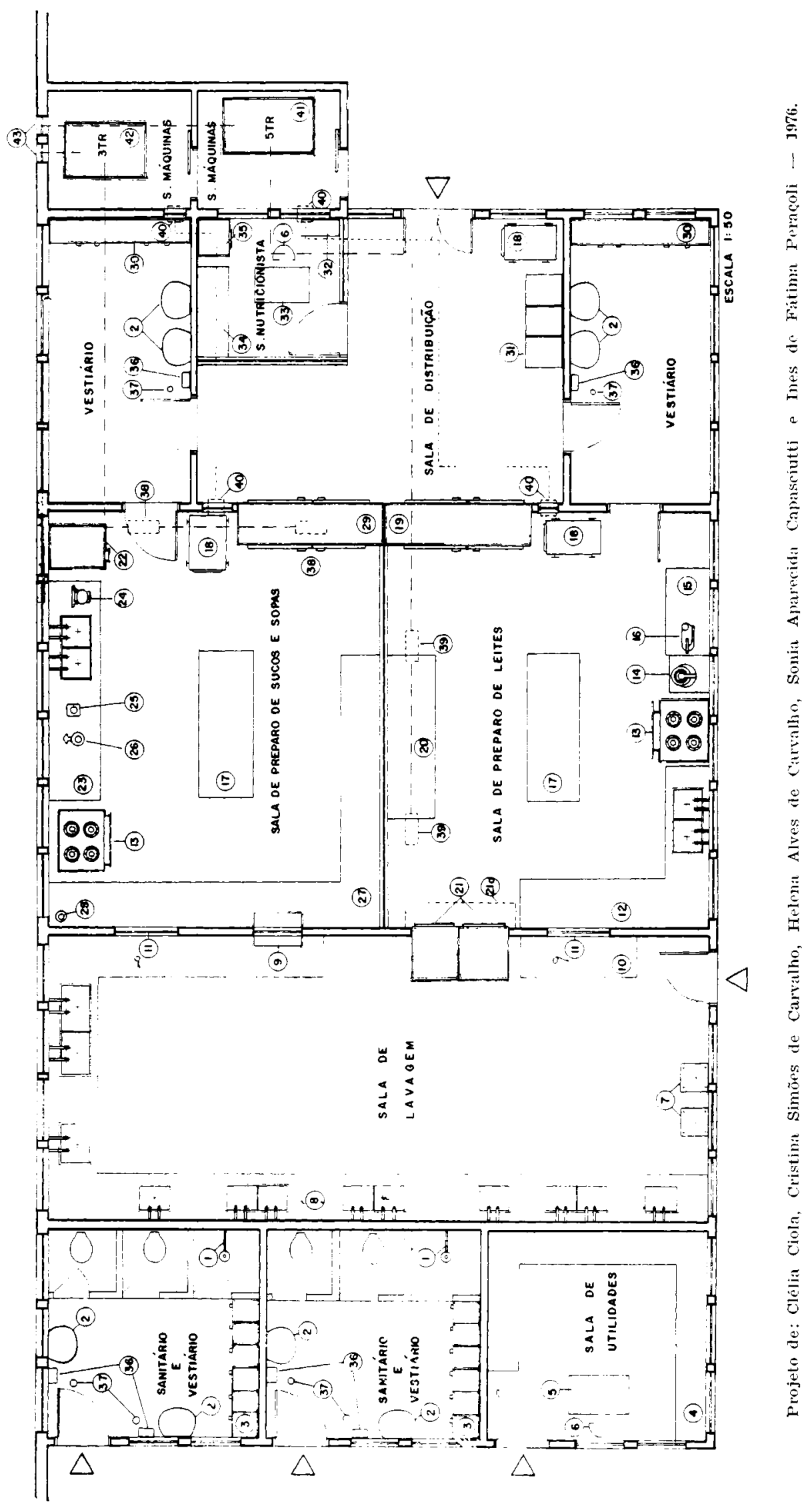

